\title{
Vasogenic shock physiology
}

This article was published in the following Dove Press journal:

Open Access Emergency Medicine

2 January 2011

Number of times this article has been viewed

\section{Sotiria Gkisioti Spyros D Mentzelopoulos}

Department of Intensive Care Medicine, University of Athens Medical School, Evaggelismos General Hospital, Athens, Greece
Correspondence: Sotiria Gkisioti Spyros D Mentzelopoulos

Department of Intensive Care Medicine, University of Athens Medical School, Evaggelismos General Hospital, Ipsilandou 45-47, GR 10675, Athens, Greece

Tel +30697 7465832

Fax +302I0 32I 8493

Email sogiria@yahoo.gr
Abstract: Shock means inadequate tissue perfusion by oxygen-carrying blood. In vasogenic shock, this circulatory failure results from vasodilation and/or vasoplegia. There is vascular hyporeactivity with reduced vascular smooth muscle contraction in response to $\alpha 1$ adrenergic agonists. Considering vasogenic shock, one can understand its utmost importance, not only because of its association with sepsis but also because it can be the common final pathway for long-lasting, severe shock of any cause, even postresuscitation states. The effective management of any patient in shock requires the understanding of its underlying physiology and pathophysiology. Recent studies have provided new insights into vascular physiology by revealing the interaction of rather complicated and multifactorial mechanisms, which have not been fully elucidated yet. Some of these mechanisms, such as the induction of nitric oxide synthases, the activation of adenosine triphosphate-sensitive potassium channels, and vasopressin deficiency, have gained general acceptance and are considered to play an important role in the pathogenesis of vasodilatory shock. The purpose of this review is to provide an update on the pathogenesis of vasogenic shock.

Keywords: nitric oxide synthases, $\mathrm{K}_{\text {ATP }}$ channels, vasopressin, $\mathrm{H}_{2} \mathrm{~S}$, vasoplegic syndrome

\section{Introduction}

In 1971, Weil and Shubin reclassified four states of shock: hypovolemic, cardiogenic, obstructive, and distributive shock. ${ }^{1}$ In the first three states, tissue hypoperfusion is a result of decreased cardiac output. In distributive shock, however, hypoperfusion results from circulatory dysfunction, leading to an abnormal distribution of a normal or even increased cardiac output. ${ }^{1}$ Vasodilatory shock, which could be considered a form of distributive shock, is characterized by two major factors: hypotension, due to failure of the vascular smooth muscle to constrict, and poor response to vasopressor therapy, due to hyporeactivity to catecholamines.

Sepsis is the most frequent cause of vasodilatory shock. Other causes include inadequate tissue oxygenation (eg, hypoxic lactic acidosis, carbon monoxide intoxication) and prolonged and severe hypotension (eg, postresuscitation states, late-phase hemorrhagic or cardiogenic shock, and vasoplegia after cardiopulmonary bypass). Also, shock states with probable vasodilation include glucocorticoid deficiency, anaphylaxis, liver failure, and cyanide poisoning. Nevertheless, vasogenic shock can be the final common pathway for long-lasting, severe shock from any cause. ${ }^{2}$

Despite recent intense research, the mechanisms of vasogenic shock have not been elucidated yet. This is probably due to the pathophysiology involved. However, some mechanisms have gained general acceptance and are considered to play an important submit your manuscript $\mid$ www.dovepress.com

Dovepress

DOI: $10.2147 /$ OAEM.S10388
Open Access Emergency Medicine 20 I I:3 I-6

(C) 201 I Gkisioti and Mentzelopoulos, publisher and licensee Dove Medical Press Ltd.This is an Open Access article which permits unrestricted noncommercial use, provided the original work is properly cited. 
role in the pathogenesis of vasodilatory shock. Thus, the goal of this review is to analyze these mechanisms.

Most of the research has been conducted in septic shock. Similar mechanisms are likely involved in the pathophysiology of vasogenic shock due to other causes, although generalizations should be made with caution.

Sepsis is a major cause of vasodilatory shock. The fact that purified endotoxin derived from Gram-negative organisms can cause vascular collapse when injected was first noticed in $1899 .{ }^{3}$ However, it is also widely accepted that the outcome of sepsis is determined mainly by the host response to infection, rather than by the insulting microorganism itself. ${ }^{4}$ As soon as the endotoxin is recognized by host immune cells, a highly complex inflammatory cascade is triggered, which involves many pro- and anti-inflammatory mediators and cytokines. This causes a release of powerful secondary mediators that further amplify the process.

\section{Role of nitric oxide in vasogenic shock}

Nitric oxide (NO) is a mediator that is causally involved in vasogenic shock. NO was originally described as an endothelium-derived relaxing factor of vascular smooth muscle. ${ }^{5}$ Since then, NO has been widely recognized as a vasodilator during sepsis. ${ }^{6}$

The enzymes responsible for NO production are the nitric oxide synthases (NOS). The endothelial isoform (eNOS) is responsible for basal NO production, which can increase for a short time, producing small amounts of NO. During sepsis, the role of eNOS is not yet fully clarified. It seems that its activity increases and then decreases in a later phase. ${ }^{7}$ The inducible form (iNOS), on the other hand, is expressed when triggered by proinflammatory agents such as endotoxin, tumor necrosis factor alpha (TNF- $\alpha)$, interferon gamma (IFN- $\gamma$ ), and interleukin (IL)-1, IL-2, and IL-6, and produces much larger amounts of NO, provided that L-arginine is available. ${ }^{8}$ L-arginine is the substrate for NO biosynthesis, and its availability can be increased directly by cytokines and endotoxin, leading to a different pathway of increasing NO synthesis during sepsis. ${ }^{7}$ Recent studies show the importance of neuronal NOS (nNOS) in the regulation of the circulatory system. nNOS is located in sympathetic and parasympathetic nerve endings but also in cardiac myocytes modulating calcium influx and, perhaps, inflammatory signaling and microcirculatory responses during sepsis. ${ }^{9}$ Table 1 summarizes the action of NOS isoforms.

From a macrocirculatory point of view, NO plays a very important role in blood pressure and organ blood
Table I Production of NO in health and vasogenic shock

\begin{tabular}{lll}
\hline $\begin{array}{l}\text { No production } \\
\text { pathway }\end{array}$ & Normal states & Vasogenic shock \\
\hline Endothelial NOS & $\begin{array}{l}\text { Basal production of } \\
\text { NO (small amounts) }\end{array}$ & $\begin{array}{l}\text { NO production } \\
\text { increases at shock onset } \\
\text { and then decreases }\end{array}$ \\
Inducible NOS & & $\begin{array}{l}\text { Activity triggered by } \\
\text { proinflammatory agents. }\end{array}$ \\
& & $\begin{array}{l}\text { Produces large amounts } \\
\text { of NO during sepsis }\end{array}$ \\
Neuronal NOS & & May contribute to the \\
& regulation of vascular & $\begin{array}{l}\text { May modulate calcium } \\
\text { influx and participate } \\
\text { in the circulatory }\end{array}$ \\
& smooth muscle tone. & \begin{tabular}{l} 
responses during sepsis \\
\hline
\end{tabular}
\end{tabular}

Notes: ${ }^{\text {TTh }}$ Thithway probably plays a minor role in the associated pathophysiology. ${ }^{b}$ This NOS isoform is located in sympathetic and parasympathetic nerve fiber endings and in cardiac myocytes.

Abbreviations: NO, nitric oxide; NOS, nitric oxide synthase.

flow regulation, mainly by reducing intracellular calcium, thus causing relaxation of vascular smooth muscle and vasodilation..$^{10}$ Excess NO production due to induction of NOS, and especially iNOS, may be the cause of vasodilation and vasoplegia during sepsis and in the late phase of hemorrhagic shock. ${ }^{2,11}$ Elevated concentrations of NO breakdown products were found in septic animals and patients, and in many studies, inhibitors of NOS increased arterial pressure and vascular resistance in septic animals and humans. ${ }^{9}{ }^{12}$ Similar results were presented by studying patients with decompensated hemorrhagic shock. ${ }^{13}$ However, the use of nonspecific NOS inhibitors did not improve mortality in septic patients, although hypotension was effectively managed, ${ }^{14}$ which might imply a "loose" relationship between macro- and microcirculation; ${ }^{15}$ in addition, resuscitation of the mean blood pressure or cardiac output alone is inadequate in sepsis, although this could be considered only as one interpretation of the trial results. Recent studies suggest that nNOS and eNOS may have a protective role in sepsis and that selective iNOS inhibition might be beneficial. ${ }^{9}$

Furthermore, the role of NO in vascular hyporesponsiveness during vasogenic shock seems to be of great importance. This hyporeactivity involves not only adrenergic stimulation but also other vasoactive agents, eg, angiotensin II and histamine. ${ }^{11}$ One possible mechanism of this action is probably the direct activation by $\mathrm{NO}$ of potassium channels that are sensitive to cytosolic calcium. ${ }^{2}$ However, a recent animal study suggests another mechanism that does not involve calcium mobilization or entry. ${ }^{16}$

NO overproduction during sepsis may also be the cause of direct myocardial depression. ${ }^{17}$ 
Despite NO's detrimental effects on the systemic circulation, it is important to mention that NO plays a very important role in the preservation of microcirculation. Microcirculation includes the arterioles, terminal arterioles, capillaries, and post-capillary and collecting venules but can be functionally divided into resistance, exchange, and capacitance vessels. ${ }^{18}$ Under normal states, $\mathrm{NO}$ is responsible for the maintenance of microcirculatory homeostasis. During an insult, it seems to preserve microcirculatory patency and function. ${ }^{19}$ Microcirculatory heterogeneity, often due to NO production, is evident in various organs and within any organ itself, matching the oxygen supply with the organs' metabolic demands. ${ }^{20}$ During sepsis, the systemic NO overproduction is also unevenly distributed to different microvascular beds, leading to vulnerable microcirculatory units, with NO deficiency. ${ }^{19}$ Oxygen-carrying blood is shunted through these units during distributive shock, resulting in an oxygen demand-supply imbalance, which differs in various organ beds for different shock states. ${ }^{21}$ Shunting of oxygen transport is an important pathogenic feature of distributive shock. ${ }^{22}$ As a result, $\mathrm{NO}$ overproduction might even play a protective role in the disturbed microvascular perfusion by improving the mismatch of oxygen supply and demand. ${ }^{11,19}$

During vasoplegic syndrome after cardiopulmonary bypass, NO seems to play an important role by causing vasodilation and vascular hyporesponsiveness, ${ }^{23}$ although a non-NO-dependent mechanism seems to also be crucial. ${ }^{24}$

\section{Vasogenic shock and ATP-sensitive potassium channels ( $K_{\text {ATP }}$ channels)}

The most interesting feature concerning adenosine triphosphate-sensitive potassium $\left(\mathrm{K}_{\text {ATP }}\right)$ channels is that they are being blocked by micromolar intracellular concentrations of ATP, thus remaining mostly inactive under normal conditions. A fall in ATP level, due to compromised oxygen supply, as can happen during several shock states, leads to channel opening. Other substances, such as kinases, phosphatases, G-proteins, phospholipids, intracellular calcium, vasoactive hormones, eg, calcitonin gene-related peptide (CGRP), adenosine, atrial natriuretic peptide, prostacyclin, vasopressin, endothelin, and angiotensin II, can regulate channel opening or closure as well. ${ }^{25}$ During sepsis, activation of $\mathrm{K}_{\mathrm{ATP}}$ channels may be due to NO overproduction, a rise in CGRP, disruption of actin cytoskeleton, or tissue dysoxia. ${ }^{25}$ Activation of $\mathrm{K}_{\mathrm{ATP}}$ channels was also described in moderate hemorrhagic and cardiogenic shock, probably due to tissue disoxya, although a neurohormonal mechanism may also play a role. ${ }^{2}$
The significance of $\mathrm{K}_{\text {ATP }}$ channels in the modulation of arterial smooth muscle tone in septic conditions was first recognized in $1989 .{ }^{26}$ Since then, numerous animal in vivo and organ bath studies have pointed to $\mathrm{K}_{\text {ATP }}$ channels for both hypotension and vascular hyporeactivity during sepsis. ${ }^{11,25}$

Another interesting observation is that dexamethasone improved vascular hyporeactivity to catecholamines in rats treated with lipopolysaccharide (LPS), probably due to $\mathrm{K}_{\text {ATP }}$ activity inhibition by the steroid. ${ }^{27}$ This observation might imply a possible mechanism of glucocorticoids' beneficial effects when used during sepsis or other vasodilatory conditions, besides their anti-inflammatory properties. Hydrocortisone treatment is known to improve the response to adrenergic agonist infusion and to facilitate shock reversal, ${ }^{28}$ which is also the reason for being recommended by the Surviving Sepsis Campaign for septic patients with poor response to fluid resuscitation and vasopressor therapy. ${ }^{29}$

However, a recent placebo-controlled study seems to question the role of $\mathrm{K}_{\text {ATP }}$ channels in sepsis-associated vascular hyporeactivity, ${ }^{30}$ whereas another study on septic mice treated with LPS implies an even more beneficial role of $\mathrm{K}_{\text {ATP }}$ channel activation. ${ }^{31}$

Another noteworthy issue is vasorelaxation caused by hydrogen sulfide $\left(\mathrm{H}_{2} \mathrm{~S}\right) . \mathrm{H}_{2} \mathrm{~S}$ has been a well known toxic pollutant for the past 300 years. However, recent studies demonstrate that it is also synthesized by mammalian tissues from L-cysteine metabolism. ${ }^{32}$ During the last decade, $\mathrm{H}_{2} \mathrm{~S}$ established a role as the third endogenous gaseous transmitter, together with NO and CO (carbon monoxide). ${ }^{33,34}$ In humans, it is produced mainly in the cardiovascular system, brain, liver, and kidney. ${ }^{35}$ In the cardiovascular system, L-cysteine is metabolized mainly by the enzyme CSE (cystathionine $\gamma$-lyase), resulting in $\mathrm{H}_{2} \mathrm{~S}$ production. ${ }^{36}$ In earlier studies, the vasorelaxant effect of $\mathrm{H}_{2} \mathrm{~S}$ was already recognized. These early studies demonstrated that $\mathrm{H}_{2} \mathrm{~S}$ relaxed rat aortic tissues in vitro. ${ }^{37}$ This action seemed to be only partly endothelium dependent and completely independent of the activation of the circular guanosine monophosphate (cGMP) pathway, unlike NO. In isolated vascular smooth muscle cells, $\mathrm{H}_{2} \mathrm{~S}$ directly increased $\mathrm{K}_{\text {ATP }}$ channel activity. ${ }^{36,38}$

Current data suggest that $\mathrm{H}_{2} \mathrm{~S}$ exerts its actions through a variety of interrelated mechanisms. ${ }^{39}$ Regarding its vasodilatory effect, numerous studies have demonstrated that its most important mechanism of action is through direct activation of $\mathrm{K}_{\text {ATP }}$ channels. An endothelium-dependent mechanism seems to also be important and may comprise direct inhibition of the angiotensin-converting enzyme, inhibition of oxidative phosphorylation, or augmentation of NO vasodilatory action ${ }^{34}$ (Table 2). However, the interaction between 
Table 2 Possible vasodilatory mechanisms of $\mathrm{H}_{2} \mathrm{~S}$

\section{Nonendothelium dependent}

Direct activation of of $\mathrm{K}_{\text {ATP }}$ channels

Endothelium dependent

Direct inhibition of the angiotensin-converting enzyme

Inhibition of oxidative phosphorylation

Augmentation of NO vasodilatory action

Abbreviations: $\mathrm{H}_{2} \mathrm{~S}$, hydrogen sulfide; $\mathrm{K}_{\text {ATP }}$, adenosine triphosphate-sensitive potassium; NO, nitric oxide.

$\mathrm{H}_{2} \mathrm{~S}$ and $\mathrm{NO}$ seems to be more complicated. Recent studies suggest that low doses of $\mathrm{H}_{2} \mathrm{~S}$ may induce vasoconstriction by scavenging endothelial NO. ${ }^{40,41}$ It may be noteworthy that NO and $\mathrm{CO}$ also activate $\mathrm{K}_{\text {ATP }}$ channels, but this effect is indirect and cGMP mediated. ${ }^{42} \mathrm{H}_{2} \mathrm{~S} \mathrm{~K}_{\text {ATP }}$ channel activation is direct and non-cGMP dependent. This property makes it unique among vasodilatory gases.

The involvement of $\mathrm{H}_{2} \mathrm{~S}$ in the pathophysiology of vasodilatory shock was noticed in several animal models of hemorrhagic shock, sepsis, and endotoxic shock. ${ }^{43-46}$ Another recent study in LPS-injected rats suggested that inhibition of $\mathrm{H}_{2} \mathrm{~S}$ had a protective effect that was independent of hemodynamics. ${ }^{47}$

Excessive activation of $\mathrm{K}_{\mathrm{ATP}}$ channels is clearly implicated in vasodilatory shock states, although there is no doubt that further investigation is needed to clarify several issues concerning their physiologic and pathophysiologic role.

\section{Role of vasopressin in vasodilatory shock}

Arginine vasopressin is a nonapeptide that is synthesized by the magnocellular neurons of the hypothalamus and mediates vasoconstriction via activation of V1-receptors of vascular smooth muscle and antidiuresis via activation of V2-receptors in the renal collecting ducts. ${ }^{48}$ The most potent regulators of vasopressin release are increased plasma osmolality and severe hypovolemia and hypotension. Other stimulators may be pain, nausea, hypoxia, hormones, and mediators such as acetylcholine, histamine, nicotine, dopamine, prostaglandins, angiotensin II, and other catecholamines. ${ }^{49}$

In health, vasopressin has little effect on regulation of blood pressure. During shock states, however, vasopressin seems to play a crucial role, showing a biphasic response. In early shock, 20-200-fold increases in vasopressin levels are noticed, whereas prolonged shock states are associated with a fall in vasopressin levels. ${ }^{48}$ Late-phase vasopressin depletion was confirmed in vasodilatory septic shock, latephase hemorrhagic or cardiogenic shock, unresponsiveness to volume replacement and catecholamine administration, vasoplegic syndrome after cardiopulmonary bypass, and hemodynamically unstable organ donors ${ }^{50}$ (Table 3 ). The exact mechanism underlying this deficiency remains to be determined. Potential mechanisms include depletion of neurohypophyseal stores, autonomic dysfunction, and increased release of $\mathrm{NO}$ within the posterior pituitary, which may downregulate vasopressin production..$^{50}$

Another interesting feature is the remarkable response of patients with vasodilatory shock to exogenous vasopressin administration, even in shock states resistant to other vasoconstrictors. The mechanisms for this exquisite sensitivity are also multifactorial. Some of these factors may include: 1) low plasma concentration of the endogenous hormone, leaving vascular receptors available for occupation by exogenous vasopressin; 2) increased vasoconstricting potency of vasopressin, under conditions of sympathetic denervation; 3) vasopressin-induced augmentation of norepinephrine-induced vasoconstriction; 4) direct activation of $\mathrm{K}_{\text {ATP }}$ channels; and 5) the vasopressin-induced inhibition of $\mathrm{NO}$ and atrial natriuretic peptide action. $^{2}$

The relative deficiency of vasopressin in septic shock and the restoration of plasma vasopressin to an appropriate level after low-dose vasopressin infusion was once more confirmed by a recent multicenter, randomized, double-blind trial of vasopressin versus norepinephrine in septic shock (VASST [Vasopressin and Septic Shock Trial]). ${ }^{51}$ In that study's prospectively defined stratum of less severe septic shock, mortality was lower (by $9.2 \%, P=0.05$ ) in the vasopressin-treated group. In addition, the combination of vasopressin and corticosteroids seems to also decrease mortality in septic shock, relative to norepinephrine and corticosteroids. ${ }^{52}$ Similar results were also shown by a study of our own, when treating patients with postresuscitation shock. ${ }^{53}$ These results may introduce a new role for vasopressin in vasodilatory conditions.

\section{Other mechanisms of vasogenic shock}

Induction of NOS, activation of $\mathrm{K}_{\text {ATP }}$ channels, and vasopressin deficiency are the most studied mechanisms contributing to vasogenic shock pathophysiology. Intense research on

Table 3 Shock states associated with vasopressin depletion

I. Vasodilatory septic shock

2. Late-phase hemorrhagic shock

3. Late-phase cardiogenic shock

4. Vasoplegic syndrome after CABG

5. Hemodynamic instability in organ donors

Abbreviation: CABG, coronary artery bypass graft. 
this important and rather complicated issue has led to the recognition of other mechanisms, with still unclear contribution and significance, necessitating further investigation.

Atrial and brain natriuretic peptide are well known vasodilators. Their plasma levels were found to be significantly increased in recent clinical studies of septic shock. ${ }^{54,55}$ However, the exact mechanism of this overproduction is not fully determined, and nor are their role and value. ${ }^{10}$

Other investigators suggest that severe sepsis should be considered as a neuroendocrine disorder. ${ }^{56}$ In particular, the autonomic nervous system might play an important role in vasodilatory shock, as the depletion of the sources of endogenous catecholamines also contributes to circulatory failure. ${ }^{57}$ Neurohormonal activators of $\mathrm{K}_{\text {ATP }}$ channels may also be involved in some forms of vasodilatory shock. ${ }^{2}$

Lastly, high levels of arachidonic acid metabolites, like prostaglandins, leukotrienes, and thromboxane, are found in increased plasma concentrations in septic patients. These mediators cause vasodilation, leucocyte activation, and damage to vascular endothelial cells, although their role in vasodilatory shock seems to be less important. ${ }^{8}$

\section{Concluding remarks}

It is clear that the pathogenesis of vasodilatory shock warrants further study.

In consideration of the role of NO, its detrimental effects on macrocirculation are recognized and accepted, but recent advances in research reveal an important and possibly protective role of NO in the preservation of the microcirculation. This new perspective needs further investigation, especially since it has become clear that optimizing global hemodynamic parameters in patients in shock does not necessarily resuscitate the microcirculation, which could be far more important.

The principal role of $\mathrm{K}_{\mathrm{ATP}}$ channel activation in the pathogenesis of vasodilatory shock has been questioned by recent research. However, the recognition of the vasodilatory activity of $\mathrm{H}_{2} \mathrm{~S}$ has led to new perspectives regarding the importance of the interaction among $\mathrm{H}_{2} \mathrm{~S}, \mathrm{~K}_{\text {ATP }}$ channels and NO.

More research is needed to clarify the role of vasopressin in vasodilatory conditions. Although its importance is recognized, many questions need to be answered with respect to its mechanisms of action.

In conclusion, our understanding of the physiology and pathophysiology of vasodilatory shock has improved during the last decade, but many questions still remain unresolved. The complexity and variety of the mechanisms involved make this task difficult and time consuming. However, new research results may well lead to the development of a new generation of specific and more effective treatments.

\section{Disclosure}

The authors report no conflicts of interest in this work.

\section{References}

1. Weil MH, Shubin H. Proposed reclassification of shock states with special reference to distributive defects. Adv Exp Med Biol. 1971;23: $13-23$.

2. Landry DW, Oliver JA. The pathogenesis of vasodilatory shock. NEngl J Med. 2001;345:588-595.

3. Romberg E, Pässler H, Bruhns C, Müller W. Untersuchungen über die allgemeine Pathologie and Therapie der Kreislaufstörung bie acuten Infectionskrankheiten. Arch Klin Med. 1899;64:652-714.

4. Cohen J. The immunopathogenesis of sepsis. Nature. 2002;420: 885-891.

5. Ignarro LJ, Buga GM, Wood KS, Byrns RE, Chaudhuri G. Endotheliumderived relaxing factor produced and released from artery and vein is nitric oxide. Proc Natl Acad Sci U S A. 1987;84:9265-9269.

6. Hauser B, Bracht H, Matejovic M, Radermacher P, Venkatesh B. Nitric oxide synthase inhibition in sepsis? Lessons learned from large-animal studies. Anesth Analg. 2005;101:488-498.

7. Chandra A, Enkhbaatar P, Nakano Y, Traber LD, Traber DL. Sepsis: emerging role of nitric oxide and selectins. Clinics. 2006;61(1): $71-76$.

8. Young JD. The heart and circulation in severe sepsis. Br J Anaesth. 2004;93:114-120.

9. Hollenberg SM, Cinel I. Bench-to-bedside review: nitric oxide in critical illness-update 2008. Crit Care. 2009;13:218.

10. Kotsovolis G, Kallaras K. The role of endothelium and endogenous vasoactive substances in sepsis. Hippokratia. 2010;14:88-93.

11. Matsuda N, Hattori Y. Vascular biology in sepsis: pathophysiological and therapeutic significance of vascular dysfunction. Smooth Muscle Res. 2007;43:117-137.

12. Murray PT, Wylam ME, Umans JG. Nitric oxide and septic vascular dysfunction. Anesth Analg. 2000;90:89-89.

13. Shah NH, Billiar TR. Role of nitric oxide in inflammation and tissue injury during endotoxemia and hemorrhagic shock. Environ Health Perspect. 1998;106:1139-1143.

14. Lopez A, Lorente JA, Steingrub J, et al. Multiple-center, randomized, placebo-controlled, double blind study of the nitric oxide synthase inhibitor 546C88: effect on survival in patients with septic shock. Crit Care Med. 2004;32:21-30.

15. De Backer D, Ortiz JA, Salgado D. Coupling microcirculation to systemic hemodynamics. Curr Opin Crit Care. 2010;16:250-254.

16. Farmer MR, Roberts RE, Gardiner SM, Ralevic V. Effects of in vivo lipopolysaccharide infusion on vasoconstrictor function of rat isolated mesentery, kidney, and aorta. J Pharmacol Exp Ther. 2003; 306:538-545.

17. Silva E, Passos RDH, Ferri MB, Poli de Figueiredo LF. Sepsis: from bench to bedside. Clinics. 2008;63:109-120.

18. Tyagi A, Sethi AK, Girotra G, Mohta M. The microcirculation in sepsis. Ind J Anaesth. 2009;53:281-293.

19. Trzeciak S, Cinel I, Phillip Dellinger R, et al; Microcirculatory Alterations in Resuscitation and Shock (MARS) Investigators. Resuscitating the microcirculation in sepsis: the central role of nitric oxide, emerging concepts for novel therapies, and challenges for clinical trials. Acad Emerg Med. 2008;15:399-413.

20. De Backer D, Hollenberg S, Boerma C, et al. How to evaluate the microcirculation: report of a round table conference. Crit Care. 2007; 11:R101.

21. Dyson A, Stidwill R, Taylor V, Singer M. Tissue oxygen monitoring in rodent models of shock. Am J Physiol Heart Circ Physiol. 2007;293: $526-533$. 
22. Elbers PW, Ince C. Mechanisms of critical illness - classifying microcirculatory flow abnormalities in distributive shock. Crit Care. 2006;10:221.

23. Evora PR, Ribeiro PJ, Vincente WV, et al. Methylene blue for vasoplegic syndrome treatment in heart surgery: fifteen years of questions, answers, doubts and certainties. Rev Bras Cir Cardiovasc. 2009; 24:279-288

24. Shanmugam G. Vasoplegic syndrome - the role of methylene blue. Eur J Cardiothorac Surg. 2005;28:705-710.

25. Buckley J, Singer M, Clapp L. Role of KATP channels in sepsis. Cardiovasc Res. 2006;72:220-230.

26. Standen NB, Quayle JM, Davies NW, Braiden JE, Huang Y, Nelson MT. Hyperpolarizing vasodilators activate ATP-sensitive $\mathrm{K}$ channels in arterial smooth muscle. Science. 1989;245:177-180.

27. D'Emmanuele di Villa Bianca R, Lippolis L, Autore G, et al. Dexamethasone improves vascular hyporeactivity induced by LPS in vivo by modulating ATP-sensitive potassium channels activity. Br J Pharmacol. 2003;140:91-96.

28. Japiassu AM, Salluh JI, Bozza PT, Bozza FA, Castro-Faria-Neto HC. Revisiting steroid treatment for septic shock: molecular actions and clinical effects - a review. Mem Inst Oswaldo Cruz. 2009; 104: 531-548.

29. Dellinger RP, Levy MM, Carlet JM, et al. Surviving Sepsis Campaign: international guidelines for management of severe sepsis and septic shock. Crit Care Med. 2008;36:1394-1396.

30. Warrillow S, Egi M, Bellomo R. Randomized, double-blind, placebo-controlled crossover pilot study of a potassium channel blocker in patients with septic shock. Crit Care Med. 2006;34: 980-985.

31. Kane GC, Lam C-F, O'Cochlain F, et al. Gene knockout of the KCNJ8encoded Kir6.1 $\mathrm{K}_{\text {ATP }}$ channel imparts fatal susceptibility to endotoxemia. FASEB J. 2006;20:2271-2280.

32. Stipanuk MH. Sulfur amino acid metabolism: pathways for production and removal of homocysteine and cysteine. Annu Rev Nutr. 2004; 24:539-577.

33. Lowicka E, Beltowski J. Hydrogen sulfide $\left(\mathrm{H}_{2} \mathrm{~S}\right)$ - the third gas of interest for pharmacologists. Pharmacol Rep. 2007;59:4-24.

34. Wagner F, Asfar P, Calzia E, Radermacher P, Szabo P. Bench-to-bedside review: hydrogen sulfide - the third gaseous transmitter: applications for critical care. Crit Care. 2009;13(3):213.

35. Doeller JE, Isbell TS, Benavides G, Koenitzer J, Patel H, Patel RP, Lancaster JR Jr. Polarographic measurement of hydrogen sulfide production and consumption by mammalian tissues. Anal Biochem. 2005; 341:40-51.

36. Zhao W, Zhang J, Lu Y, Wang R. The vasorelaxant effects of $\mathrm{H}_{2} \mathrm{~S}$ as a novel endogenous gaseous KATP channel opener. EMBO J. 2001; 20:6008-6016.

37. Hosoki R, Matsuki N, Kimura H. The possible role of hydrogen sulfide as an endogenous smooth muscle relaxant in synergy with nitric oxide. Biochem Biophys Res Commun. 1997;237:527-531.

38. Zhao W, Wang R. $\mathrm{H}_{2} \mathrm{~S}$-induced vasorelaxation and underlying cellular and molecular mechanisms. Am J Physiol Heart Circ Physiol. 2002; 283:474-480.

39. Szabó C. Hydrogen sulphide and its therapeutic potential. Nat Rev Drug Discov. 2007;6:917-935.
40. Ali MY, Ping CY, Mok YY, et al. Regulation of vascular nitric oxide in vitro and in vivo; a new role for endogenous hydrogen sulphide? Br J Pharmacol. 2006;149:625-634.

41. Webb GD, Lim LH, Oh VM, et al. Contractile and vasorelaxant effects of hydrogen sulfide and its biosynthesis in the human internal mammary artery. J Pharmacol Exp Ther. 2008;324:876-882.

42. Murphy ME, Brayden JE. Nitric oxide hyperpolarizes rabbit mesenteric arteries via ATP-sensitive potassium channels. J Physiol. 1995;486: 47-58.

43. Mok YY, Atan MS, Yoke Ping C, et al. Role of hydrogen sulphide in hemorrhagic shock in the rat: protective effect of inhibitors of hydrogen sulphide biosynthesis. Br J Pharmacol. 2004;143:881-889.

44. Hui Y, Du J, Tang C, Bin G, Jiang H. Changes in arterial hydrogen sulfide content during septic shock and endotoxic shock in rats. J Infect. 2003;47:155-160.

45. Li L, Bhatia M, Zhu YZ, et al. Hydrogen sulfide is a novel mediator of lipopolysaccharide-induced inflammation in the mouse. FASEB J. 2005;19:1196-1198.

46. Zhang H, Zhi L, Moore PK, Bhatia M. Role of hydrogen sulfide in cecal ligation and puncture-induced sepsis in the mouse. Am J Physiol Lung Cell Mol Physiol. 2006;290:1193-1201.

47. Collin M, Anuar FB, Murch O, Bhatia M, Moore PK, Thiemermann C. Inhibition of endogenous hydrogen sulfide formation reduces the organ injury caused by endotoxemia. Br J Pharmacol. 2005;146:498-505.

48. Holmes CL, Landry DW, Grandon J. Science review: vasopressin and the cardiovascular system part 1 - receptor physiology. Crit Care. 2003; $7: 427-434$

49. Holmes CL, Patel BM, Russell JA, Walley KR. Physiology of vasopressin relevant to management of septic shock. Chest. 2001;120: 989-1002.

50. Holmes CL, Landry DW, Grandon J. Science review: vasopressin and the cardiovascular system part 2 - clinical physiology. Crit Care. 2004; 8:15-23.

51. Russell JA, Walley KR, Singer J, et al. Vasopressin versus norepinephrine infusion in patients with septic shock. $N$ Engl J Med. 2008;358: 877-887.

52. Russell JA, Walley KR, Gordon AC, Cooper J, et al. Interaction of vasopressin infusion, corticosteroid treatment, and mortality of septic shock. Crit Care Med. 2009;37:811-818.

53. Mentzelopoulos SD, Zakynthinos SG, Tzoufi M, et al. Vasopressin, epinephrine, and corticosteroids for in-hospital cardiac arrest. Arch Intern Med. 2009;169:15-24.

54. Witthaut R, Busch C, Fraunberger P, et al. Plasma atrial natriuretic peptide and brain natriuretic peptide are increased in septic shock: Impact of interleukin-6 and sepsis-associated left ventricular dysfunction. Intensive Care Med. 2004;29:1696-1702.

55. Rudiger A, Gasser S, Fischler M, Hornemann T, von Eckardstein A, Maggiorini M. Comparable increase of B-type natriuretic peptide and amino-terminal pro-B-type natriuretic peptide levels in patients with severe sepsis, septic shock, and acute heart failure. Crit Care Med. 2006;34:2140-2144.

56. Munford RS, Tracey KJ. Is severe sepsis a neuroendocrine disease? Mol Med. 2002;8:437-442.

57. Rittirsch D, Flierl MA, Ward PA. Harmful molecular mechanisms in sepsis. Nat Rev Immunol. 2008;8:776-787.
Open Access Emergency Medicine

\section{Publish your work in this journal}

Open Access Emergency Medicine is an international, peer-reviewed, open access journal publishing original research, reports, editorials, reviews and commentaries on all aspects of emergency medicine. The manuscript management system is completely online and includes a very quick and fair peer-review system, which is all easy to use.

\section{Dovepress}

Visit http://www.dovepress.com/testimonials.php to read real quotes from published authors. 